Opening Closed Minds:

The Combined Effects of Intergroup Contact and Need for Closure on Prejudice

Kristof Dhont, Arne Roets, \& Alain Van Hiel

Ghent University, Department of Developmental, Personality and Social Psychology

Running head: Intergroup Contact x Need for Closure

Word count: Approx 9900

E-mail addresses: Kristof.Dhont@,UGent.be, Arne.Roets@,UGent.be,

Alain.VanHiel@,UGent.be

Corresponding Author: Kristof Dhont, Department of Developmental, Personality and

Social Psychology, Henri Dunantlaan 2, B-9000, Ghent, Belgium, e-mail address:

Kristof.Dhont@UGent.be

Funding:

This research was supported by a PhD research grant from the Ghent University Research

Council (BOF) awarded to Kristof Dhont (\#01D23607) under supervision of Alain Van

Hiel. Arne Roets is a post-doctoral researcher supported by the Research Foundation Flanders (FWO).

Acknowledgements:

We are grateful to Joke Lannoye for her help with parts of the data collection 


\begin{abstract}
Five studies tested whether Need for Closure (NFC) moderates the relationship between intergroup contact and prejudice toward immigrants. The results consistently showed that intergroup contact was more strongly associated with reduced levels of prejudice among people high in NFC compared to people low in NFC. Studies $1(N=138$ students) and $2(N=294$ adults $)$ demonstrated this moderator effect on subtle, modern, and blatant racism. Study 2 also replicated the moderator effect for extended contact. An experimental field study (Study $3 ; N=60$ students) provided evidence of the causal direction of the moderator effect. Finally, Studies $4(N=125$ students) and $5(N=135$ adults) identified intergroup anxiety as the mediator through which the moderator effect influences modern and blatant racism as well as hostile tendencies toward immigrants. The role of motivated cognition in the relationship between intergroup contact and prejudice is discussed.
\end{abstract}

Key words: prejudice; intergroup contact; Need for Closure; intergroup anxiety; racism 
Opening Closed Minds:

The Combined Effects of Intergroup Contact and Need for Closure on Prejudice

Frequent positive contact between members of different groups has been considered one of the most powerful strategies to promote positive intergroup attitudes and reduce intergroup bias (Allport, 1954; Brown \& Hewstone, 2005; Dovidio, Gaertner, \& Kawakami, 2003; Pettigrew, 1998). Over the last two decades, empirical evidence coming from longitudinal (e.g., Levin, van Laar, \& Sidanius, 2003), cross-sectional (e.g., Ellison \& Powers, 1994), experimental (e.g., Desforges et al., 1991), and meta-analytic (e.g., Pettigrew \& Tropp, 2006) studies have corroborated the contact hypothesis, demonstrating its validity and applicability across a wide variety of groups and settings.

However, more than five decades ago, Allport (1954) argued that the effect of situational variables like intergroup contact on prejudice depends on a person's character structure. Recapitulating this suggestion, Pettigrew and Tropp (2006, see also Hodson, 2009; Pettigrew, 1998) insisted that individual differences were important as well, and over the years, several researchers have empirically demonstrated the value of examining the moderating role of individual difference variables while studying intergroup processes (e.g., Britt, Boniecki, Vescio, Biernat, \& Brown, 1996; Dhont \& Van Hiel, 2009; in press; Hodson, Harry, \& Mitchell, 2009; Mendoza-Denton, Downey, Purdie, Davis, \& Pietrzak, 2002; Page-Gould, Mendoza-Denton, \& Tropp, 2008).

The present research builds on the situation $x$ person approach to prejudice and investigated the interplay between intergroup contact and individual differences in motivated social cognition (i.e., the Need for Closure). Moreover, we investigated whether intergroup anxiety can explain this interaction effect. 
According to Allport (1954), contact with members of an outgroup can successfully reduce prejudice toward this outgroup, at least when contact occurs under the specific preconditions of equal status, intergroup cooperation, the pursuit of common goals, and the presence of institutional support. Pettigrew and Tropp's (2006) metaanalysis of 515 studies confirmed that "Intergroup contact typically reduces intergroup prejudice” (p. 766), showing a moderate mean effect size, $r=-.21$, for the impact of intergroup contact on negative outgroup attitudes.

Although these meta-analytic results corroborate Allport's (1954) main thesis on the benefits of intergroup contact, further refinements and extensions of the contact hypothesis have also been proposed (e.g., Brown \& Hewstone, 2005; Pettigrew 1998). For example, Allport's preconditions (e.g., equal status) are now generally accepted as facilitators rather than as necessary conditions to achieve the effects of intergroup contact (Pettigrew \& Tropp, 2006).

Another important extension of the contact paradigm pertains to the extended contact hypothesis, originally proposed by Wright, Aron, McLaughlin-Volpe, and Ropp (1997), which asserts that having ingroup acquaintances who maintain positive contact with outgroup members is also associated with reduced prejudice. During the past decade, correlational and (quasi-)experimental support for this hypothesis has accumulated, demonstrating that people who witness contact between in- and outgroup members report lower levels of outgroup prejudice than those without extended contact experiences (Paolini, Hewstone, Cairns, \& Voci, 2004; Tam, Hewstone, Kenworthy, \& Cairns, 2009; Turner, Hewstone, Voci, \& Vonofakou, 2008; Wright et al., 1997). The effect of extended contact is especially important for those people with limited or no opportunity to directly interact with outgroup members (Turner et al., 2008; Wright et al., 1997). 
Contemporary contact researchers have also elaborated on the underlying mechanisms that explain how contact works. Specifically, they have highlighted the mediating role of affective processes such as empathy and intergroup anxiety (Paolini et al., 2004; Pettigrew \& Tropp, 2008; Voci \& Hewstone, 2003) as well as cognitive processes such as inclusion of the outgroup in the self and perceived intergroup norms (Hodson et al., 2009; Turner et al., 2008).

\section{Individual Differences in Motivated Social Cognition}

Allport (1954) argued that not only situational factors (i.e., intergroup contact), but also individual differences in general cognitive style play an important role in prejudice. Indeed, Allport stated that “a person's prejudice is unlikely to be merely a specific attitude to a specific group; it is more likely to be a reflection of his whole habit of thinking about the world he lives in" (p. 175). In particular, he clarified that people prone to prejudice prefer a clearly structured world and they like "order, but especially social order" (p. 404). They also "feel more secure when they know the answers" (p. 402) and have "a marked need for definiteness; they cannot tolerate ambiguity" (p. 175). Moreover, a prejudiced-prone person is said to be narrow-minded and "fails to see all relevant sides to his problem" (p. 402). In sum, Allport (1954) suggested that prejudicedprone people exhibit - among other things - a preference for order and predictability, a dislike of ambiguity, and a show of narrow-mindedness. From Allport's work it can thus be straightforwardly inferred that prejudice should be understood as an expression of how a person thinks about the social world, that is, in terms of motivated cognition.

During the last two decades, the motivated social cognition perspective, aiming to explain people's subjective knowledge and beliefs about the social world, has regained substantial scholarly attention. In particular, in his work on lay epistemics, Kruglanski (1989) argued that a cognitive style (e.g., cognitive rigidity) and subjective knowledge 
about social reality stems from particular motivational needs rather than being merely a cognitive deficit. A prominent concept in this renewed approach is the Need for Closure (NFC, Kruglanski, 1989; Kruglanski \& Webster, 1996), referring to the individual's desire for firm answers and aversion toward ambiguity.

Represented by the five facet scales that constitute the NFC scale (Webster \& Kruglanski, 1994), people with a high level of dispositional NFC prefer order and structure in their lives, abhorring unconstrained chaos and disorder. They also prefer predictability, which is reflected in a desire for secure and stable knowledge that is reliable across circumstances and unchallenged by exceptions. People high in NFC also experience an urgent desire to reach closure in judgments, reflected in their need for decisiveness. They feel discomfort with ambiguity; experiences without closure are viewed as aversive. Finally, they are closed-minded, reflected in an unwillingness to have their knowledge challenged by alternative opinions or inconsistent evidence (Webster \& Kruglanski, 1994).

Overall, these facets that constitute NFC are strikingly similar to the cognitive style characteristics that Allport (1954) held responsible for prejudice development. Nevertheless, although Allport explicitly associated this motivated cognitive style with prejudice, contemporary motivated cognition theories have a much broader scope, accounting for how people process information and structure their knowledge and ideas. For example, NFC has been shown to affect a range of phenomena including the extent of information processing and hypothesis generation, subjective confidence in decisions, numerical anchoring, as well as primacy and recency effects (for an overview, see Kruglanski \& Webster, 1996). Additionally, various studies have focused on the influence of NFC on authoritarianism, essentialism, political conservatism, and prejudice (e.g., Roets \& Van Hiel, 2006, in press; Van Hiel, Pandelaere, \& Duriez, 2004). The wide 
variety of both social and non-social phenomena influenced by NFC attests to its importance in understanding knowledge construction.

\section{Need for Closure: Moderator of Intergroup Contact Effects}

While emphasizing the role of motivated social cognition in prejudice, Allport (1954) suggested that a person's cognitive style affects the extent to which prejudice can be changed through situational influences. According to Allport, intergroup contact is precluded from having strong effects in rigid people exactly because of their way of thinking. In particular, a person with a rigid cognitive style "does not change his mental set easily, but persists in old ways of reasoning" (p. 175). Moreover, the assertion that cognitively rigid people resist the influence of intergroup contact corresponds to the tendency of high NFC people to freeze on existing ideas, exemplified by the desire to consolidate previous knowledge and the resistance to reconsider prior knowledge and attitudes (Kruglanski \& Webster, 1996). Translating Allport's (1954) suggestion in terms of NFC, it can thus be inferred that a high NFC poses a motivational-cognitive barrier that prevents beneficial effects of contact to reduce prejudice. In other words, we may hypothesize that positive intergroup contact is associated with reduced prejudice when NFC is low, whereas this relationship is less pronounced or even absent when NFC is high. We refer to this possibility by Hypothesis 1 a.

However, even though early thinking (e.g., Allport, 1954) predicts the type of interaction proposed by Hypothesis 1a, more recent work suggests a different view of the interplay between intergroup contact and NFC. In particular, people high in NFC are assumed to experience feelings of discomfort, resistance, and even fear of unfamiliar stimuli. Obviously, outgroups and intergroup situations may constitute such unfamiliar and unknown "stimuli". Indeed, Mous et al. (2010) demonstrated that people high in NFC 
showed more psychophysiological stress when interacting with an unknown outgroup member compared to people low in NFC.

In the contact literature, feelings of uncertainty and fear experienced in intergroup contexts are referred to as intergroup anxiety (Stephan \& Stephan, 1985) and have frequently been associated with negative outgroup attitudes. Most relevant in this regard, positive intergroup contact reduces intergroup anxiety, a well-documented finding established in a variety of real-world intergroup contact situations, such as cross-group friendships in college (Levin et al., 2003), among Muslims and Hindus in Bangladesh (Islam \& Hewstone, 1993), British and Japanese students (Greenland \& Brown, 1999), and Catholics and Protestants in Northern Ireland (Paolini et al., 2004). Moreover, PageGould, et al. (2008) have shown that among people who are predisposed to experiencing intergroup anxiety, intergroup contact not only decreases self-reported anxiety but also cortisol reactivity (a stress hormone). Frequent intergroup encounters often disconfirm negative expectations (Mendoza-Denton, Page-Gould, \& Pietrzak, 2006; Page-Gould et al., 2008) and thereby attenuate intergroup anxiety, which in turn, may lead to less prejudice.

Intergroup contact does not aim to explicitly challenge existing attitudes, nor does intergroup contact confront people with what "right" or "wrong" attitudes are. Hence, unlike direct, confronting strategies (e.g., through education programs) that explicitly aim to reduce prejudice, subtle influences of intergroup contact are unlikely to be deflected by the motivational-cognitive barrier of people high in NFC. Moreover, intergroup contact may successfully reduce prejudice among high NFC people because of the potential of intergroup contact to decrease feelings of uncertainty and anxiety in intergroup contexts. Our alternative hypothesis, referred to as Hypothesis $1 \mathrm{~b}$, therefore states that frequent positive intergroup contact is most strongly related to lower levels of prejudice among 
people high in NFC, whereas this relationship is less pronounced or absent among people low in NFC.

\section{The Present Research}

The present work is the first explicit examination of the impact of motivated cognition in the relationship between intergroup contact and prejudice. As outlined above, by combining the intergroup contact and NFC literatures, we contrast two competing hypotheses regarding the moderating role of NFC on the effect of intergroup contact on prejudice.

Hypothesis 1a is based on Allport's (1954) writings and states that the effect of intergroup contact on prejudice is less pronounced or absent among people high in NFC compared to people low in NFC. In this case, high NFC levels should act as a motivational-cognitive barrier. Alternatively, Hypothesis $1 \mathrm{~b}$ states that intergroup contact reduces prejudice when NFC is high whereas its impact is less pronounced or absent when NFC is low. Furthermore, this moderation effect is expected to be mediated by intergroup anxiety.

To test these competing hypotheses, we conducted five studies among Flemish Belgians, focusing on contact with and prejudice toward non-European immigrants, especially people from countries with a Muslim majority. Moroccans and Turks constitute the two largest immigrant communities in Belgium. In Studies 1 and 2, we tested the moderator hypotheses in a sample of undergraduate students and adults, respectively. Study 2 also investigated whether NFC moderates the relationship between extended contact and prejudice. Study 3 tested the causal direction of the moderation effect in an experimental field study. Studies 4 and 5 investigated whether the moderation effect of NFC is mediated via intergroup anxiety. By including hostile tendencies toward immigrants as a dependent variable, Study 5 also extended the results of Studies 1-4. 
Study 1

Method

\section{Participants}

A total of 138 undergraduate psychology students ( $75 \%$ women, $M_{\text {age }}=19.21$, $\left.S D_{\text {age }}=2.88\right)$ participated as part of a classroom exercise. We assessed respondents' nationality and religious views to ensure that they did not belong to the target outgroup. All respondents were Belgian nationals; none were Muslim (57\% Christians, 43\% atheists, agnostics, or non-religious people).

\section{Measures}

Intergroup Contact. To obtain a single index of frequent positive contact (cf., Voci \& Hewstone, 2003; Tam et al., 2009), four questions measured the amount of positive contact (Dhont \& Van Hiel, 2009). These items were completed on 7-point Likert scales $(1=$ never; 7 = very frequently). Sample items include, "How often do you have pleasant contact with immigrants?" and "How often do you have positive experiences with immigrants until now?"

Need for Closure. Participants completed 41 items of the revised NFC questionnaire (for the original scale, see Kruglanski, Webster, \& Klem, 1993; for the revised items, see Roets \& Van Hiel, 2007) on Likert scales anchored by 1 (certainly disagree) and 6 (certainly agree). Sample items include, "I like to have friends who are unpredictable" (reverse scored), "I do not usually consult many different opinions before forming my own view", and "When I have made a decision, I feel relieved".

Racial Prejudice. Participants completed measures of modern (McConahay, 1986, see also Dhont, Cornelis, \& Van Hiel, 2010) and subtle racism (Pettigrew \& Meertens, 1995; see also Van Hiel \& Mervielde, 2005) on 5-point Likert scales (1 = strongly disagree; 5 = strongly agree). These more inconspicuous forms of racism are 
more appropriate to measure racism among psychology students who are generally less likely to hold or express blatant racist views.

The modern racism scale (ten items) consisted of three facet scales: denial of continuing discrimination, (three items; e.g., "Discrimination against immigrants is no longer a problem in Belgium"), antagonism toward immigrants' demands (three items; e.g., "Immigrants are getting too demanding in their push for equal rights"), and resentment about special favors for immigrants, (four items; e.g., "Immigrants receive too little attention in the media"; reverse scored).

The subtle racism scale (eight items) consisted of four items assessing defense of tradition (e.g., "Immigrants living in Belgium teach their children values and skills different from those required to be successful in our society") and four items assessing the denial of positive emotions (e.g., "I admire the immigrant community members who live here under difficult circumstances"; reverse scored).

Table 1 presents the descriptive statistics and the correlations among these measures.

\section{Insert Table 1 about here}

\section{Results and Discussion}

To test the moderation effect of NFC on the relationship between intergroup contact and racial attitudes, we first centered NFC and intergroup contact scores and then calculated their interaction term by multiplying these centered scores (Aiken \& West, 1991). We tested a multivariate regression model in which intergroup contact, NFC, and their interaction term were included as predictors of both modern and subtle racism. The multivariate test yielded significant main effects of intergroup contact, $F(2,133)=8.90, p$ $<.001$, and NFC, $F(2,133)=3.11, p<.05$, as well as a significant interaction effect, $F(2,133)=9.61, p<.001$. 
To investigate the interaction effect in greater detail and to test the incremental validity of this interaction effect on both dependent variables, two hierarchical regression analyses were tested with modern racism or subtle racism as the dependent variable. In both analyses, the centered scores of NFC and intergroup contact were entered in the first step and their interaction term was entered in the second step.

The first analysis revealed that intergroup contact and NFC explained a significant portion of the variance in modern racism, $R^{2}=.08, p<.005$ and yielded significant main effects of intergroup contact, $\beta=-.18, p<.05$, and NFC, $\beta=.21, p=.01$. Adding the interaction term in the second step of the regression significantly increased the variance explained, $R^{2}$ change $=.05, \beta=-.22, p<.01$.

The second analysis revealed that intergroup contact and NFC also explained a significant portion of the variance in subtle racism, $R^{2}=.11, p<.001$, with a significant main effect of intergroup contact, $\beta=-.33, p<.001$, but not of NFC, $\beta=.07$, ns. The interaction term significantly increased the variance explained, $R^{2}$ change $=.11, \beta=-.34$, $p<.001$.

Figure 1 depicts the relationship between intergroup contact and modern (Panel A) and subtle (Panel B) racism at high and low levels of NFC (i.e., one SD above and below the mean, respectively). Simple slopes analyses indicated that intergroup contact is significantly related to modern and subtle racism when NFC is high, $\beta=-.40, p<.001$ and $\beta=-.67, p<.001$, respectively, but not when NFC is low, $\beta=.05, n s$ and $\beta=.03, n s$, respectively.

The findings of Study 1 support Hypothesis $1 \mathrm{~b}$ showing that the negative relationship between intergroup contact and prejudice is especially pronounced among people high in NFC, whereas this relationship is absent when NFC is low. Hence, the 
present results refute Hypothesis 1a stating that a high NFC operates as a motivationalcognitive barrier preventing the beneficial effects of contact on prejudice.

\section{Insert Figure 1 about here}

Study 2

The goal of Study 2 was twofold. First, we aimed to replicate the moderator effect of NFC in the relationship between intergroup contact and prejudice in a heterogeneous sample of adults using a measure of blatant prejudice. Blatant racism refers to a more traditional, overt, and direct form of racism, also denoted as "old-fashioned racism". Second, we investigated whether NFC also moderates the relationship between extended contact and prejudice.

\section{Method}

\section{Participants}

To obtain a heterogeneous sample, undergraduate psychology students distributed the questionnaires among their adult neighbors. Students were instructed only to recruit non-Muslim, Belgian citizens. These demographics were double-checked by directly asking respondents' nationality and religion. We collected 294 questionnaires (74\% Christians, $26 \%$ atheists, agnostics, non-religious people, or other). The sample ( $M_{\text {age }}=$ $\left.47.91, S D_{\text {age }}=4.75\right)$ consisted of $68 \%$ women and $27 \%$ men; $5 \%$ did not indicate their sex. With respect to educational level, 16\% had attended university, $42 \%$ had completed higher education, $26 \%$ had completed secondary school, $11 \%$ had earned lower scholarly degrees, and 5\% did not indicate their educational level.

\section{Measures}

Intergroup Contact and NFC. Respondents completed the measure of positive contact as well as the NFC questionnaire administered in Study 1. 
Extended Intergroup Contact. Two items (based on Turner et al., 2008), completed on 7-point Likert scales ( $1=$ none; $7=$ many $)$, assessed respondent's level of extended contact, asking (1) whether they know many native Belgian people within their circle of acquaintances who get along well with immigrants and (2) how many people within their circle of native Belgian friends have immigrants as friends.

Racial Prejudice. We administered a nine-item Likert scale measure of blatant racism $(1=$ strongly disagree; 5 = strongly agree; see also Duriez \& Van Hiel, 2002). Sample items include, "In general, immigrants are not to be trusted" and "We have to keep our race pure and fight interracial mixture".

Table 1 presents descriptive statistics and correlations among the measures.

\section{Results and Discussion}

Similar to Study 1, the centered scores of direct intergroup contact and NFC were entered in the first step of a hierarchical regression analysis as predictors of blatant racism; their interaction term was entered in the second step. Direct intergroup contact and NFC explained a significant portion of the variance in blatant racism, $R^{2}=.25, p<$ .001 . There were significant main effects of direct contact, $\beta=-.28, p<.001$, and NFC, $\beta$ $=.37, p<.001$. Furthermore, adding the interaction term significantly increased the variance explained, $R^{2}$ change $=.02, \beta=-.13, p=.01$.

A similar regression model with extended contact (instead of direct contact) and NFC as predictors of blatant racism was also significant, $R^{2}=.27, p<.001$. There were significant main effects of extended contact, $\beta=-.33, p<.001$, and NFC, $\beta=.33, p<$ .001. Again, adding the interaction term significantly increased the variance explained, $R^{2}$ change $=.01, \beta=-.10, p<.05$.

Figure 2 depicts the relationship between direct (Panel A) or extended contact (Panel B) and blatant racism at high and low levels of NFC (i.e., one SD above and below 
the mean, respectively). As in Study 1, simple slope analyses revealed a strong effect of direct contact when NFC was high, $\beta=-.41, p<.001$. When NFC was low, however, this relationship was substantially weaker, $\beta=-.18, p<.01$. We obtained a similar interaction pattern with extended contact, revealing a pronounced association between extended contact and blatant racism among people high in NFC, $\beta=-.42, p<.001$. Alternatively, this relationship was weaker among people low in $\mathrm{NFC}, \beta=-.23, p=.001$.

In sum, this second study, conducted in an adult sample with a measure of blatant racism, corroborated Hypothesis $1 \mathrm{~b}$ and replicated the results of Study 1, indicating the strongest effects of intergroup contact in the high NFC group. Furthermore, we demonstrated a similar result for extended contact.

\section{Insert Figure 2 about here}

Study 3

Studies 1 and 2 revealed that NFC moderates the relationship between intergroup contact and prejudice. However, the cross-sectional nature of these data warrants caution when making causal inferences about the direction of these relationships. Therefore, in

Study 3, we conducted an experimental field study to compare a naturalistic high quality contact condition to a control condition to draw causal inferences.

\section{Method}

\section{Participants and Procedure}

Sixty high school students ( $75 \%$ women, $M_{\text {age }}=16.61, S D_{\text {age }}=1.38 ; 64 \%$

Christians, $36 \%$ atheists or non-religious people) from two Belgian schools participated. We recruited students at each school from classes that were collectively involved in an intercultural exchange program. These students $(N=26)$ went on a one-week school trip to Morocco and composed the experimental group. The goal of the program was to become acquainted with Moroccan students as well as with their school, religion, and 
way of life. The Belgian and Moroccan students spent much time together and were involved in joint activities, such as hiking, sightseeing, visiting the families of the Moroccan students, organizing a party, and so on. This one-week school trip is thus an exemplary contact-based intervention program including all facilitating contact conditions.

The control group consisted of students $(N=34)$ from two other classes at the same schools who did not participate in the exchange program. Because the choice to participate or not to participate was not decided by the students, selection bias was eliminated. All participants completed measures of NFC and prejudice within two weeks after the experimental group returned from Morocco.

\section{Measures}

We assessed NFC with the NFC-scale used in Studies 1 and $2(\alpha=.84, M=3.88$, $S D=.47$ ). Using a modified version of the 'General Evaluation Scale' (Wright et al., 1997), we measured general outgroup attitudes as the dependent variable. Participants described how they felt about Moroccans in general by using four 7-point differential scales: cold/warm, positive/negative, hostile/friendly, and contempt/respect. The items were coded so that higher scores indicated more negative attitudes, resulting in a reliable index $(\alpha=.90, M=4.14, S D=1.51)^{1}$

\section{Results and Discussion}

A univariate ANCOVA with condition (contact versus control condition) as the between-subjects variable and NFC (centered) with the interaction of NFC and condition as covariates, revealed a significant main effect of condition, $F(1,56)=9.85, p<.005$. Participants in the experimental group $(M=3.50)$ had less negative outgroup attitudes than participants in the control group $(M=4.63)$. There was no main effect of NFC $F(1$, 
$56)=.05, p=.82$. More importantly, this analysis yielded a significant interaction effect between condition and NFC, $F(1,56)=4.31, p<.05$, depicted in Figure 3 .

\section{Insert Figure 3 about here}

Simple slopes analyses demonstrated significantly less negative outgroup attitudes in the contact condition compared to the control condition among people high in NFC (one $\mathrm{SD}$ above the mean), $F(1,56)=13.33, p<.001$. Conversely, we did not find significant differences between the conditions among people low in NFC (one SD below the mean), $F(1,56)=.53, p=.47$. In other words, the results of Study 3 corroborated the findings of Studies 1, 2, and Hypothesis $1 \mathrm{~b}$, as well as further demonstrated a causal effect of intergroup contact on prejudice among people high in NFC but not among people low in NFC.

\section{Study 4}

Having demonstrated that the degree to which intergroup contact reduces prejudice depends on the levels of NFC, we aimed to determine the process underlying this moderation effect in Study 4. We focused on one of the most robust mediating mechanisms through which intergroup contact reduces prejudice: intergroup anxiety (Brown \& Hewstone, 2005; Paolini et al., 2004; Paolini, Hewstone, Voci, Harwood, \& Cairns, 2006; Pettigrew \& Tropp, 2008; Voci \& Hewstone, 2003).

As we argued in the introduction, people high in NFC are especially prone to experience feelings of discomfort and fear of what is unfamiliar, ambiguous, or unpredictable. Therefore, we hypothesized that the potential for intergroup contact to decrease feelings of uncertainty and fear during intergroup encounters is a central mechanism through which prejudice reduction among people high in NFC occurs. In other words, the effects of contact on intergroup anxiety may explain the pronounced association between contact and prejudice reduction among people high in NFC. 


\section{Method}

\section{Participants}

A total of 125 undergraduate students $\left(63 \%\right.$ women, $\left.M_{\text {age }}=18.60, S D_{\text {age }}=1.61\right)$ participated in return for course credit. Only non-Muslim Belgians participated in the study.

\section{Measures}

Intergroup contact, NFC, and modern racism were assessed with the same measures as used in Study 1. After completing these scales, a modified version of the intergroup anxiety scale developed by Stephan and Stephan (1985) assessed respondents' levels of intergroup anxiety (see, e.g., Paolini et al., 2004). Respondents reported the extent to which they felt anxious, nervous, insecure, frightened, or scared when interacting with immigrants on 7-point Likert scales $(1=$ definitely not; $7=$ definitely $)$. Table 2 shows descriptive statistics and correlations among the measures.

\section{Insert Table 2 about here}

Results

\section{Moderation Analyses}

We conducted a hierarchical regression analysis (referred to as Model 1) with the centered scores of NFC and intergroup contact entered in Step 1 and their interaction term entered in Step 2 as predictors of racism. Table 3 shows that a main effect of intergroup contact was obtained, whereas NFC did not yield a main effect. In addition, in line with Studies 1-3, a significant interaction effect between intergroup contact and NFC emerged. Figure 4 Panel A reveals a similar pattern of results compared to previous studies. Moreover, simple slopes analyses confirmed a pronounced relation between intergroup contact and racism when NFC was high (one SD above the mean), $\beta=-.63, p$ 
$<.001$; conversely, a weaker relationship emerged when NFC was low (one SD below the mean), $\beta=-.28, p=.01$.

\section{Insert Table 3 about here}

We conducted a second hierarchical regression analysis (Model 2) in which we tested the predictive value of contact and NFC on intergroup anxiety (see Table 3 ). We obtained a main effect of intergroup contact, but not of NFC. Adding the interaction term in Step 2 significantly increased the variance explained. Figure 4 Panel B plots this interaction and shows that intergroup contact was strongly and negatively associated with intergroup anxiety when NFC was high (one SD above the mean), $\beta=-.65, p<.001$. Conversely, a weaker relationship was obtained among people low in NFC (one SD below the mean), $\beta=-.24, p<.05$.

\section{Insert Figure 4 about here}

\section{Mediated Moderation}

To test whether intergroup anxiety accounts for the interaction between intergroup contact and NFC on racism, we conducted a series of regression analyses following the recommendations of Muller, Judd, and Yzerbyt (2005). To test the hypothesized mediated moderation, three regression models needed to be examined, two of which were reported above. As these analyses show, we obtained a significant intergroup contact $\mathrm{x}$ NFC interaction effect on racism (i.e., the target variable) as well as on intergroup anxiety (i.e., the mediator). The third regression model to be tested includes intergroup contact, $\mathrm{NFC}$, and intergroup anxiety as well as the intergroup contact $\mathrm{x}$ NFC and the NFC $\mathrm{x}$ intergroup anxiety interaction terms as predictors of racism.

As reported in the last column of Table 3, this third regression model (Model 3) revealed a significant main effect of intergroup contact and intergroup anxiety and a marginally significant main effect of NFC. The two interaction terms were non- 
significant. Because a significant effect of intergroup anxiety on racism emerged, and the residual intergroup contact $\mathrm{x}$ NFC interaction was reduced to non-significance, the requirements for mediated moderation were fulfilled. Hence, we can conclude that the interaction of contact and NFC on racism is mediated through intergroup anxiety. Additional Sobel tests confirmed that the mediation effect of intergroup anxiety was significant among people high in NFC, $z=2.10, p<.05$, but not among people low in $\mathrm{NFC}, z=1.12, p=.30$.

\section{Discussion}

In line with Hypothesis $1 \mathrm{~b}$ and replicating the findings in Studies 1-3, the results of Study 4 show a strong negative relationship between intergroup contact and prejudice among people high in NFC. Conversely, this relationship was curbed among people low in NFC. Moreover, our findings showed that this moderation effect was mediated by intergroup anxiety. Thus, the reduction in intergroup anxiety can be considered the underlying mechanism that explains why intergroup contact most strongly reduces prejudice among people high in NFC. In other words, because intergroup contact decreases feelings of intergroup uncertainty, unfamiliarity, and its associated anxiety, people who experience uncertainty and unfamiliarity as highly aversive (i.e., those high in NFC) benefit the most from the effects of intergroup contact.

\section{Study 5}

Study 5 aimed to cross-validate the mediated moderation obtained in Study 4 using a measure of modern and blatant racism within a heterogeneous sample of adults. Additionally, we broadened the scope of our dependent variables by including a measure of hostile behavioral tendencies. Traditional contact research typically investigates contact effects on the affective and cognitive components of outgroup attitudes and racism. However, several researchers have recently stressed the importance of examining 
contact effects on the behavioral tendency component of prejudice because these tendencies constitute more proximal variables of real-world intergroup behavior (e.g., Plant \& Devine, 2003; Paolini, Hewstone, \& Cairns, 2007; Tam, et al., 2009).

\section{Method}

\section{Participants}

The sample was recruited by two research students who contacted their parents' social networks. The sample $(N=135)$ consisted of $58 \%$ women and $42 \%$ men. Mean age was 41.69 years $(S D=14.15)$ and all respondents reported being non-Muslim and Belgian (68\% Christians, 32\% atheists, agnostics, non-religious people, or other).

\section{Measures}

Similar to Studies 1-4, we assessed intergroup contact, NFC, intergroup anxiety, modern racism, and blatant racism. Given that Study 4 assessed intergroup anxiety at the end of the questionnaire, intergroup anxiety scores may have been contaminated by the responses on the prejudice scale. Therefore, we administered the intergroup anxiety measure between the contact and prejudice measures in Study 5. Finally, respondents completed five items on 5 -point Likert scales $(1=$ strongly disagree; $5=$ strongly agree; adapted from Plant \& Devine, 2003), to assess their hostile tendencies toward immigrants when expecting intergroup contact. These items were: "If I had to interact with immigrants, I would tend to behave more firmly and harsher", "I would behave hostile when having contact with immigrants", "I would be frustrated when interacting with immigrants", "I would look forward to interacting with immigrants" (reverse scored), and "I would be irritated in a conversation with an immigrant". Table 2 presents descriptive statistics and correlations among measures.

\section{Results and Discussion}

\section{Moderation Analyses}


First, we tested a multivariate regression model in which the centered scores of intergroup contact, NFC, and their interaction term predicted the three dependent variables simultaneously: modern racism, blatant racism, and hostile tendencies. The multivariate test yielded main effects of intergroup contact, $F(3,129)=8.15, p<.001$, and NFC, $F(3,129)=13.52, p<.001$, as well as a significant interaction effect, $F(3,129)$ $=3.62, p=.01$.

Next, separate hierarchical regression analyses were conducted with the centered scores of intergroup contact and NFC entered in Step 1 and their interaction term entered in Step 2 as predictors of modern racism (Model 1a) and blatant racism (Model 1b). Table 4 presents the results of both models and displays the main effects of intergroup contact and NFC. Again, adding the interaction term significantly increased the variance explained. Figure 5 Panels A and B plots the interaction effects. Simple slopes analyses confirmed the pronounced relationship between intergroup contact and racism when NFC was high (one SD above the mean), $\beta=-.45, p<.001$ (Model 1a) and $\beta=-.51, p<.001$ (Model 1b). Conversely, this relationship was not significant when NFC was low (one SD below the mean), $\beta=-.11, n s$ (Model 1a) and $\beta=-.11, n s$ (Model 1b).

A similar hierarchical regression analysis was conducted with hostile tendencies as the dependent variable (Model 1c), revealing effects comparable to those obtained for the other racism measures (see Table 4). Again, intergroup contact was strongly and negatively related to hostile tendencies when NFC was high (one SD above the mean), $\beta$ $=-.46, p<.001$, whereas no significant effects were found among people low in NFC (one SD below the mean), $\beta=-.17$, ns (see Figure 5 Panel C).

Finally, we investigated the effects of NFC and intergroup contact on intergroup anxiety (Model 2). The results of these analyses, reported in Table 4, correspond to the those of the previous models (Models 1a, 1b, and 1c), yielding main effects of both 
intergroup contact and NFC as well as a significant interaction effect (see Figure 5 Panel D). Intergroup contact was strongly related to intergroup anxiety among people high in NFC (one SD above the mean), $\beta=-.32, p<.005$, but was not significantly related to intergroup anxiety among people low in NFC (one SD below the mean), $\beta=.02, n s$.

\section{Insert Table 4 about here \\ Insert Figure 5 about here}

\section{Mediated Moderation}

To test whether intergroup anxiety mediated the intergroup contact $\mathrm{x}$ NFC interaction on racism, we tested additional regression models for each dependent variable (Models 3a, 3b, and 3c, for modern racism, blatant racism, and hostile tendencies, respectively). In these models, intergroup contact, NFC, and intergroup anxiety were entered along with the intergroup contact $\mathrm{x}$ NFC and NFC $\mathrm{x}$ intergroup anxiety interaction terms as predictors (Muller et al., 2005). Significant main effects of intergroup contact, NFC, and intergroup anxiety (last three columns of Table 4) were yielded, whereas the interaction terms were non-significant in Model 3a (modern racism) and Model 3c (hostile tendencies). In Model 3b (blatant racism), the intergroup contact $x$ NFC interaction was still significant but less strong compared to a model without intergroup anxiety (i.e., Model 1b).

To summarize, our analyses showed that (a) NFC moderated the effect of intergroup contact on the target variables modern racism (Model 1a), blatant racism (Model 1b), and hostile tendencies (Model 1c); (b) NFC moderated the effect of intergroup contact on the mediator intergroup anxiety (Model 2); (c) a significant effect of intergroup anxiety on modern (Model 3a) and blatant racism (Model 3b) as well as hostile tendencies (Model 3c) was obtained; and (d) entering intergroup anxiety as mediator substantially reduced the magnitude of the intergroup contact x NFC interaction 
effect (Model 3a, 3b, and 3c compared to Models 1a, 1b, and 1c, respectively). Hence, intergroup anxiety mediates the interaction of intergroup contact and NFC on modern racism as well as on hostile tendencies and partially mediates the intergroup contact $\mathrm{x}$ NFC interaction on blatant racism. Additional Sobel tests confirmed significant indirect effects through intergroup anxiety among people high in NFC, $z=2.62, p<.01, z=2.60$, $p<.01$, and $z=2.47, p=.01$, for modern racism, blatant racism, and hostile tendencies, respectively, but not among people low in NFC, all $z$ 's $<.18$.

General Discussion

The present research examined the impact of motivated cognition on the relationship between intergroup contact and prejudice. Based on the intergroup contact and NFC literatures, we advanced two competing hypotheses on the possible moderating role of NFC in the relationship between contact and prejudice. Combining Allport's (1954) theoretical insights with the NFC literature, Hypothesis 1a stated that a high dispositional NFC poses a motivational-cognitive barrier that blocks the beneficial effect of intergroup contact on prejudice. Conversely, by also considering recent theories and empirical findings on intergroup contact and anxiety, Hypothesis $1 \mathrm{~b}$ stated that intergroup contact has stronger effects on prejudice among people high in NFC compared to people low in NFC.

The results of four cross-sectional studies and an experimental field study unambiguously supported Hypothesis 1b, showing that for people high in NFC, intergroup contact was strongly related to lower levels of subtle (Study 1), modern (Studies 1, 4, and 5), and blatant racism (Studies 2 and 5) as well as to less negative outgroup attitudes (Study 3). Conversely, these contact effects on the prejudice variables were curbed (Studies 2 and 4) or not significant (Studies 1, 3, and 5) for people low in NFC. $^{2}$ 
Furthermore, the present research revealed that intergroup anxiety is an important underlying psychological mechanism explaining the moderation effect. In particular, intergroup anxiety was shown to mediate the moderator effect of NFC on the relationship between intergroup contact and modern (Studies 4 and 5) and blatant racism (Study 5). Therefore, we can conclude that particularly because intergroup contact reduces the levels of intergroup anxiety, people who are most prone to feelings of uncertainty and fear of what is unfamiliar, ambiguous, or unpredictable (i.e., high NFC scorers) benefit the most from intergroup contact.

These findings were extended in two important ways. First, the effects emerged with extended contact (Study 2) and second, we applied these findings to the behavioral tendency component of prejudice (Study 5). With respect to the first additional finding, the moderator effect of NFC with extended contact is important because some contexts may prevent personal contact with outgroup members (e.g., because of secluded work or school environments). As such, the benefits of intergroup contact can still be obtained through positive encounters between ingroup friends and outgroup members. Because intergroup anxiety was not included in Study 2, it is not yet clear whether intergroup anxiety plays a role here. Nevertheless, previous research has shown that intergroup anxiety mediates both direct and extended contact effects on prejudice (Paolini, et al., 2004; Turner, et al., 2008). Moreover, because extended contact operates without the real-time experience of actual anxiety that characterizes direct contact situations (Wright et al., 1997; Turner et al., 2008), we may infer that this lack of anxiety also contributes to the positive effects of extended contact in the high NFC group.

A second noteworthy extension is that the moderation effect of NFC was not only restricted to the influence of intergroup contact on negative beliefs and feelings toward the outgroup (as typically measured by prejudice scales), but was also generalized to the 
behavioral tendency component of prejudice. In particular, among people high in NFC, but not among people low in NFC, higher levels of intergroup contact were associated with less hostile tendencies toward immigrants. Although we did not observe discriminatory behavior, this finding suggests that the obtained results may apply to realworld behavioral reactions during intergroup encounters.

In the following sections, we elaborate on how the moderator effect between intergroup contact and NFC extends previous literature, highlighting the important role of motivated cognition in the relationship between intergroup contact and prejudice. In addition, we elaborate on the importance of the situation $\mathrm{x}$ person approach to prejudice.

\section{Increased Benefits of Intergroup Contact for Closed Minds}

Our findings provide an alternative perspective on the quite pessimistic ideas regarding the closed-minded and rigid person described in Allport's (1954) work as well as in the NFC literature. In particular, Allport doubted that intergroup contact would reduce prejudice for rigid people. He argued that because of their way of thinking and reasoning, rigid people would not benefit from situational influences such as intergroup contact. Along similar lines, people high in NFC have been described as having an inflexible way of thinking that increases their resistance to persuasion and leads to the rejection of opinions and arguments inconsistent with their current attitudes (Kruglanski, Pierro, Manetti, \& De Grada, 2006). Because of their strong desire to reach certainty and their opposition to unfamiliarity, people high in NFC seem more likely to hold on to negative outgroup stereotypes and attitudes (e.g., Roets \& Van Hiel, 2006, in press; Van Hiel, et al., 2004). It was thus suggested that people high in NFC may have a motivational-cognitive barrier that safeguards their negative opinions about outgroup members. 
In contrast to the assumptions regarding cognitively rigid persons in Allport's (1954) work and NFC theory, the present results demonstrate that people high in NFC are not necessarily unaffected by the environment. Indeed, the present research suggests that the motivational-cognitive barrier is not impermeable for the subtle influences of intergroup contact. Indeed, instead of using confronting strategies to combat prejudice (e.g., convincing people through arguments, or by implementing other information-based interventions) reducing prejudice in gentle ways, such as creating intergroup contact and thereby reducing the negative feelings of anxiety, may be more effective. Thus, we suggest that the influence of intergroup contact slips through the motivational-cognitive barrier without activating its defense mechanisms.

The present research also shows some parallels with the recent work of PageGould and colleagues (2008) who demonstrated beneficial effects of intergroup friendship in people who are most prone to experience anxiety in intergroup contexts (as indexed by their scores on race-based rejection sensitivity). In particular, these people initially displayed an amplified hormonal stress response (i.e., heightened cortisol reactivity) when meeting outgroup members. However, during three later cross-group friendship meetings, a sharp decline in cortisol reactivity was observed. In other words, repeated instances of positive intergroup contact attenuates intergroup stress and its negative consequences (Mendoza-Denton \& Page-Gould, 2008; Mendoza-Denton et al., 2006).

Interestingly, other studies have also revealed that a high NFC may evoke high stress levels when unfamiliar stimuli are processed. For example, the findings of Roets and Van Hiel (2008) suggest that task situations inducing uncertainty and ambiguity result in an acute stress response among people high in NFC. Moreover, Mous et al. (2010) reported that people high in NFC experience increased levels of 
psychophysiological distress when interacting with an unknown outgroup member. Based on the present findings, however, we expect that after subsequent positive intergroup interactions, people high in NFC would show a marked decrease in distress. Hence, a promising pathway for future research is to investigate the combined effects of NFC and intergroup contact on intergroup anxiety and prejudice using a longitudinal design and hormonal or psychophysiological indicators of stress in addition to self-report measures of intergroup anxiety.

\section{The Situation x Person Approach to Prejudice}

Recently, Hodson (2009) argued that "Nowhere is the theoretical divide between person and situation more evident than the domain of prejudice research" (p. 247). Indeed, many contact researchers ignore individual differences or consider them a nuisance to be controlled in research; however, several studies have demonstrated the utility of studying individual difference variables in intergroup contexts (e.g., Britt et al., 1996; Dhont \& Van Hiel, 2009; in press; Hodson, 2008; Hodson et al., 2009; MendozaDenton et al., 2002; Page-Gould et al., 2008).

For instance, recent studies (Dhont \& Van Hiel, 2009; in press; Hodson, 2008; Hodson et al., 2009) have investigated the interactions between intergroup contact and right-wing attitudes on prejudice, as indicated by Right-Wing Authoritarianism (RWA, Altemeyer, 1981) and Social Dominance Orientation (SDO, Pratto, Sidanius, Stallworth, $\&$ Malle, 1994). The results of these studies revealed that high authoritarian people exhibited lower levels of prejudice when they had increased contact with outgroup members, whereas limited effects of intergroup contact were found among less authoritarian people. Thus, these studies suggest that intergroup contact is especially effective for people prone to prejudice. 
The present research is in line with these previously reported interaction effects between intergroup contact and right-wing attitudes on outgroup attitudes. These studies, however, focused on the moderating role of explicitly group-related social attitudes, which are closely linked to prejudice. Conversely, the present research taps into a much broader and more general construct (i.e., motivated cognition) that directs the way in which people process, interpret, and evaluate information within their social environment, or as Allport (1954) put it, their "whole habit of thinking about the world" (p. 175). Because the NFC concept aligns well with Allport's (1954) motivational-cognitive basis of prejudice, the present research should not only be considered an important contribution to the situation $\mathrm{x}$ person approach to prejudice, but also as a test and refinement of Allport's ideas.

\section{Conclusion}

The present results revealed that the strategy of intergroup contact to reduce prejudice might be most successful for people who usually stick strongly to existing attitudes, i.e., people high in NFC. Moreover, intergroup contact seems to sort such efficient effects among these people by remediating the underlying process of intergroup anxiety. Therefore, the present research provides a better understanding of prejudice reduction, paving the way for contact-based interventions in situations characterized by discrimination. 
Notes

1. Preliminary analyses showed that the experimental and control groups were not significantly different with respect to their mean NFC levels, $F(1,60)=.14, p=.71$. Moreover, NFC was not significantly correlated with outgroup attitudes, $r<.01$. 2. In all the studies, we conducted additional analyses to test whether demographic variables such as sex, age, religious affiliation, and educational level moderated the present findings, but we did not find significant results. Additional tests for nonlinear effects of intergroup contact or NFC (e.g., including the squared terms of these variables into the regression analyses) did not yield significant effects as well. 


\section{References}

Aiken, L. S., \& West, S. G. (1991). Multiple regression: testing and interpreting interactions. Newbury Park: Sage Publications.

Allport, G. W. (1954). The nature of prejudice. Reading, MA: Addison-Wesley.

Altemeyer, R. (1981). Right-wing authoritarianism. Winnipeg: University of Manitoba Press.

Britt, T. W., Boniecki, K. A., Vescio, T. K., Biernat, M., \& Brown, L. M. (1996). Intergroup anxiety: A Person x Situation approach. Personality and Social Psychology Bulletin, 22, 1177-1188.

Brown, R., \& Hewstone, M. (2005). An integrative theory of intergroup contact. Advances in Experimental Social Psychology, 37, 255-343.

Desforges, D. M., Lord, C. G., Ramsey, S. L., Mason, J. A., Van Leeuwen, M. D., West, S. C., et al., (1991). Journal of Personality and Social Psychology, 60, 531-544.

Dhont, K., Cornelis, I., \& Van Hiel, A. (2010). Interracial Public-Police Contact: Relationships with Police Officers' Racial and Work-Related Attitudes and Behaviors. International Journal of Intercultural Relations, 34, 551-560.

Dhont, K., \& Van Hiel, A. (2009). We must not be enemies: Interracial contact and the reduction of prejudice among authoritarians. Personality and Individual Differences 46, 172-177.

Dhont, K., \& Van Hiel, A. (in press). Direct contact and authoritarianism as moderators between extended contact and reduced prejudice: Lower threat and greater trust as mediators. Group Processes and Intergroup Relations

Dovidio, J. F., Gaertner, S. L., \& Kawakami, K. (2003). Intergroup contact: The past, present, and the future. Group Processes and Intergroup Relations, 6, 5-21. 
Duriez, B., \& Van Hiel, A. (2002). The march of modern fascism. A comparison of social dominance orientation and authoritarianism. Personality and Individual Differences, 32, 1199-1213.

Ellison, C. G., \& Powers, D. A. (1994). The contact hypothesis and racial attitudes among Black Americans. Social Science Quarterly, 75, 385-400.

Greenland, K., \& Brown, R. J. (1999). Categorization and intergroup anxiety in contact between British and Japanese nationals. European Journal of Social Psychology, $29,503-521$.

Hodson, G. (2008). Interracial prison contact: The pros for (social dominant) cons. British Journal of Social Psychology 47, 325-351.

Hodson, G. (2009). The puzzling person-situation schism in prejudice-research. Journal of Research in Personality, 43, 247-248.

Hodson, G., Harry, H., \& Mitchell, A. (2009). Independent benefits of contact and friendship on attitudes toward homosexuals among authoritarians and highly identified heterosexuals. European Journal of Social Psychology, 39, 509-525.

Islam, M. R., \& Hewstone, M. (1993). Dimensions of contact as predictors of intergroup anxiety, perceived outgroup variability and outgroup attitude: An integrative model. Personality and Social Psychology Bulletin, 19, 700-710.

Kruglanski, A. W. (1989). Lay epistemic and human knowledge: Cognitive and motivational bases. New York: Plenum.

Kruglanski, A. W., Pierro, A., Mannetti, L., \& De Grada, E. (2006). Groups as epistemic providers: Need for closure and the unfolding of group-centrism. Psychological Review, 113, 84-100.

Kruglanski, A. W., \& Webster, D. M. (1996). Motivated closing of the mind: "Seizing" and "freezing." Psychological Review, 103, 263-283. 
Kruglanski, A. W., Webster, D. M., \& Klem, A. (1993). Motivated resistance and openness to persuasion in the presence or absence of prior information. Journal of Personality and Social Psychology, 65, 861-877.

Levin, S., van Laar, C., \& Sidanius, J. (2003). The effects of ingroup and outgroup friendship on ethnic attitudes in college: A longitudinal study. Group Processes and Intergroup Relations, 6, 76-92.

McConahay, J. B. (1986). Modern racism, ambivelance, and the modern racism scale. In J. F. Dovidio \& S. L. Gaertner (Eds.), Prejudice, discrimination and racism (pp. 91-126). New York: Acedemic.

Mendoza-Denton, R., Downey, G., Purdie, V. J., Davis, A., \& Pietrzak, J. (2002). Sensitivity to status-based rejection: Implications for African American students' college experience. Journal of Personality and Social Psychology, 83, 896-918.

Mendoza-Denton, R., \& Page-Gould, E. (2008). Can cross-group friendships influence minority students' well being at historically White universities? Psychological Science, 19, 933-939

Mendoza-Denton, R., Page-Gould, E., \& Pietrzak, J. (2006). Mechanisms for coping with status-based rejection expectations. In S. Levin and C. van Laar (Eds.), Stigma and group inequality: Social psychological perspectives (pp.151-170). Mahwah, NJ: Erlbaum.

Muller, D., Judd, C. M., \& Yzerbyt, V. Y. (2005). When moderation is mediated and mediation is moderated. Journal of Personality and Social Psychology, 89, 852863.

Mous, L., Samochowiec, J., Florack, A., Wänke, M., Mendes, W. B., \& Wilhelm, F. H. (2010). The moderating role of need for cognitive closure on cardiovascular 
reactions to intercultural encounters: A biopsychosocial analysis. Psychophysiology, 46, S140.

Page-Gould, E., Mendoza-Denton, R., \& Tropp, L. (2008). With a little help from my cross-group friend: Reducing anxiety in intergroup contexts through cross-group friendship. Journal of Personality and Social Psychology, 95, 1080-1094.

Paolini, S., Hewstone, M., \& Cairns, E. (2007). Direct and indirect intergroup friendship effects: Testing the moderating role of the affective-cognitive bases of prejudice. Personality and Social Psychology Bulletin, 33, 1406-1420.

Paolini, S., Hewstone, M., Cairns, E., \& Voci, A. (2004). Effects of direct and indirect cross-group friendships on judgments of Catholics and Protestants in Northern Ireland: The mediating role of an anxiety-reduction mechanism. Personality Social Psychology Bulletin, 30, 770-786.

Paolini, S., Hewstone, M., Voci, A., Harwood, J., \& Cairns, E. (2006). Intergroup contact and the promotion of intergroup harmony: The influence of intergroup emotions. In R. Brown \& D. Capozza (Eds.), Social identities: Motivational, emotional, and cultural influences (pp. 209-238). Hove, UK: Psychology Press.

Pettigrew, T. F. (1998). Intergroup contact theory. Annual Review of Psychology, 49, 6585.

Pettigrew, T. F., \& Meertens, R. W. (1995). Subtle and blatant prejudice in western Europe. European Journal of Social Psychology, 25, 57-75.

Pettigrew, T. F., \& Tropp, L. R. (2006). A meta-analytic test of intergroup contact theory. Journal of Personality and Social Psychology, 90, 751-783.

Pettigrew, T. F., \& Tropp, L. R. (2008). How does intergroup contact reduce prejudice? Meta-analytic tests of three mediators. European Journal of Social Psychology, $38,922-934$. 
Plant, E. A., \& Devine, P. G. (2003). The antecedents and implications of interracial anxiety. Personality and Social Psychology Bulletin, 26, 709-801.

Pratto, F., Sidanius, J., Stallworth, L. M., \& Malle, B. F. (1994). Social Dominance Orientation: A personality variable predicting social and political attitudes. Journal of Personality and Social Psychology, 67, 741-763.

Roets, A., \& Van Hiel, A. (2006). Need for closure relations with authoritarianism, conservative beliefs and racism: The impact of urgency and permanence tendencies. Psychologica Belgica 46, 235-352.

Roets, A., \& Van Hiel, A. (2007). Separating ability from need: Clarifying the dimensional structure of the need for closure scale. Personality and Social Psychology Bulletin, 33, 266-280.

Roets, A., \& Van Hiel, A. (2008). Why some hate to dillydally and others do not: The arousal-invoking capacity of decision-making for low and high-scoring need for closure individuals. Social Cognition, 26, 333-346.

Roets, A., \& Van Hiel, A. (in press). The role of need for closure in essentialist entitativity beliefs and prejudice: An epistemic needs approach to racial categorization. British Journal of Social Psychology. DOI: $10.1348 / 014466610 X 491567$

Stephan, W. G., \& Stephan, C. W. (1985). Intergroup anxiety. Journal of Social Issues, $41,157-176$.

Tam, T., Hewstone, M., Kenworthy, J., \& Cairns, E. (2009). Intergroup trust in Northern Ireland. Personality and Social Psychology Bulletin, 35, 45-59.

Turner, R., Hewstone, M., Voci, A., \& Vonofakou, C. (2008). A test of the extended intergroup contact hypothesis: The mediating role of intergroup anxiety, perceived 
ingroup and outgroup norms, and inclusion of the outgroup in the self. Journal of Personality and Social Psychology, 95, 843-860.

Van Hiel, A., \& Mervielde, I. (2005). Authoritarianism and social dominance orientation: Relationships with various forms of racism. Journal of Applied Social Psychology $35,2323-2344$.

Van Hiel, A., Pandelaere, M., \& Duriez, B. (2004). The impact of need for closure on conservative beliefs and racism: differential mediation by authoritarian submission and authoritarian dominance. Personality and Social Psychology Bulletin, 30, 824-837.

Voci, A., \& Hewstone, M. (2003). Intergroup contact and prejudice towards immigrants in Italy: The mediational role of anxiety and the moderational role of group salience. Group Processes and Intergroup Relations, 6, 37-54.

Webster, D. M., \& Kruglanski, A. W. (1994). Individual differences in need for cognitive closure. Journal of Personality and Social Psychology, 67, 1049-1062.

Wright, S. C., Aron, A., McLaughlin-Volpe, T., \& Ropp, S. A. (1997). The extended contact effect: Knowledge of cross-group friendships and prejudice. Journal of Personality and Social Psychology, 73, 73-90. 
Table 1. Means, standard deviations, and correlations between predictor and criterion variables in Study 1 (S1) and Study 2 (S2)

\begin{tabular}{|c|c|c|c|c|c|c|c|c|}
\hline & & Mean $(S D)$ & $\alpha$ & 2 & 3 & 4 & 5 & 6 \\
\hline \multirow[t]{2}{*}{ 1. Direct Contact } & $\mathrm{S} 1$ & $3.74(1.36)$ & .90 & & -.01 & $-.18^{*}$ & $-.33^{* * *}$ & \\
\hline & $\mathrm{S} 2$ & $3.20(1.72)$ & .96 & $.59^{* * *}$ & $-.17^{* *}$ & & & $-.34^{* * *}$ \\
\hline \multirow[t]{2}{*}{ 2. Extended Contact } & $\mathrm{S} 1$ & & & & & & & \\
\hline & $\mathrm{S} 2$ & $3.15(1.58)$ & .93 & & $-.30^{* * *}$ & & & $-.41^{* * *}$ \\
\hline \multirow[t]{2}{*}{ 3. NFC } & $\mathrm{S} 1$ & $3.65(.43)$ & .85 & & & $.21^{*}$ & .07 & \\
\hline & $\mathrm{S} 2$ & $3.84(.49)$ & .89 & & & & & $.42^{* * *}$ \\
\hline \multirow[t]{2}{*}{ 4. Modern Racism } & $\mathrm{S} 1$ & $2.83(.57)$ & .80 & & & & $.61^{* * *}$ & \\
\hline & $\mathrm{S} 2$ & & & & & & & \\
\hline \multirow[t]{2}{*}{ 5. Subtle Racism } & $\mathrm{S} 1$ & $2.87(.60)$ & .81 & & & & & \\
\hline & $\mathrm{S} 2$ & & & & & & & \\
\hline \multirow[t]{2}{*}{ 6. Blatant Racism } & $\mathrm{S} 1$ & & & & & & & \\
\hline & $\mathrm{S} 2$ & $2.21(.81)$ & .92 & & & & & \\
\hline
\end{tabular}

Note. ${ }^{*} p=.05 ;{ }^{* *} p<.01 ;{ }^{* * *} p<.001$ 
Table 2. Means, standard deviations, and correlations between predictor, mediator and criterion variables in Study 4 (S4) and Study 5 (S5)

\begin{tabular}{|c|c|c|c|c|c|c|c|c|}
\hline & & Mean $(S D)$ & $\alpha$ & 2 & 3 & 4 & 5 & 6 \\
\hline \multirow[t]{2}{*}{ 1. Contact } & $\mathrm{S} 4$ & $3.79(1.34)$ & .89 & -.12 & $-.42^{* * *}$ & $-.45^{* * *}$ & & \\
\hline & S5 & $3.23(1.31)$ & .86 & $-.17^{*}$ & $-.23^{* *}$ & $-.36^{* * *}$ & $-.41^{* * *}$ & $-.39^{* * *}$ \\
\hline \multirow[t]{2}{*}{ 2. NFC } & S4 & $3.54(.47)$ & .86 & & .07 & $.16^{\dagger}$ & & \\
\hline & S5 & $3.86(.57)$ & .90 & & $.34^{* * *}$ & $.39^{* * *}$ & $.46^{* * *}$ & $.34^{* * *}$ \\
\hline \multirow[t]{2}{*}{ 3. Intergroup anxiety } & $\mathrm{S} 4$ & $2.38(1.21)$ & .92 & & & $.40^{* * *}$ & & \\
\hline & S5 & $3.78(1.66)$ & .93 & & & $.54^{* * *}$ & $.55^{* * *}$ & $.46^{* * *}$ \\
\hline \multirow[t]{2}{*}{ 4. Modern racism } & $\mathrm{S} 4$ & $2.85(.54)$ & .78 & & & & & \\
\hline & S5 & $2.94(.64)$ & .80 & & & & $.77^{* * *}$ & $.53^{* * *}$ \\
\hline \multirow[t]{2}{*}{ 5. Blatant racism } & $\mathrm{S} 4$ & & & & & & & \\
\hline & S5 & $2.20(.88)$ & .90 & & & & & $.63^{* * *}$ \\
\hline \multirow[t]{2}{*}{ 6. Hostile tendencies } & $\mathrm{S} 4$ & & & & & & & \\
\hline & S5 & $2.10(.81)$ & .85 & & & & & \\
\hline
\end{tabular}

Note. ${ }^{\dagger} p<.08 ;{ }^{*} p<.05 ;{ }^{* *} p<.01 ;{ }^{* * *} p<.001$ 
Table 3. Results of the regression analyses tested in Study 4 ( $\beta$-values), demonstrating a intergroup contact $\mathrm{x}$ NFC interaction on racism mediated by intergroup anxiety

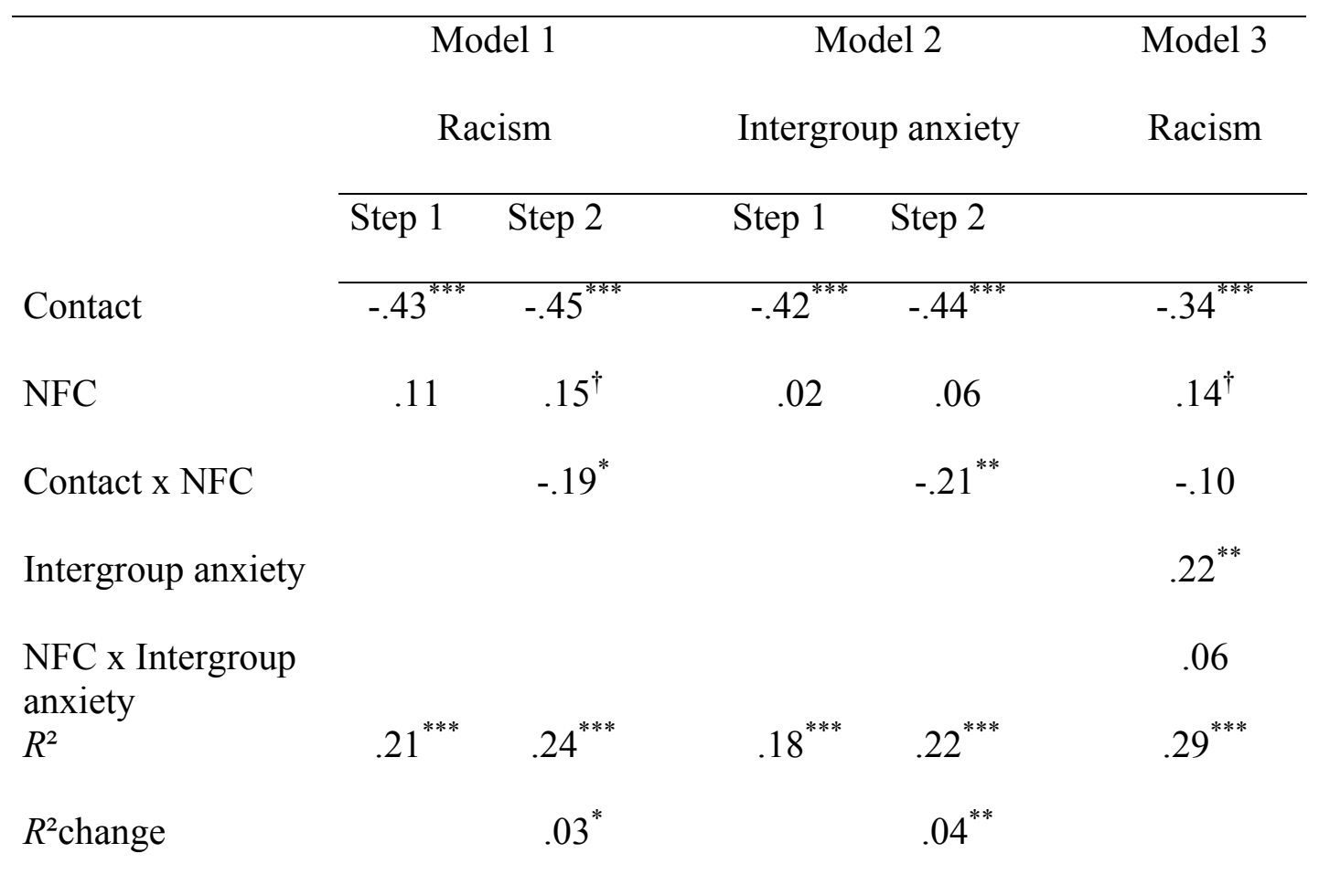

Note. ${ }^{\dagger} p<.08 ;{ }^{*} p<.05 ;{ }^{* *} p<.01 ;{ }^{* * *} p<.001$ 
Table 4. Results of the regression analyses tested in Study 5 ( $\beta$-values), demonstrating an intergroup contact $\mathrm{x}$ NFC interaction on modern, blatant racism and hostile tendencies, mediated by intergroup anxiety



Note. ${ }^{\dagger} p<.07 ;^{*} p<.05 ;{ }^{* *} p<.01 ;{ }^{* * *} p<.001$ 


\section{Figure Captions}

Figure 1. Intergroup contact $\mathrm{x}$ NFC interaction predicting modern and subtle racism (Study $1)$.

Figure 2. Intergroup contact $\mathrm{x}$ NFC interaction and extended contact $\mathrm{x}$ NFC interaction predicting blatant racism (Study 2).

Figure 3. Mean levels of negative outgroup attitudes for participants in the control versus contact condition as a function of NFC (Study 3)

Figure 4. Intergroup contact $\mathrm{x}$ NFC interaction predicting modern racism and intergroup anxiety (Study 4).

Figure 5. Intergroup contact x NFC interaction predicting modern racism, blatant racism, hostile tendencies, and intergroup anxiety (Study 5). 
Figure 1



B

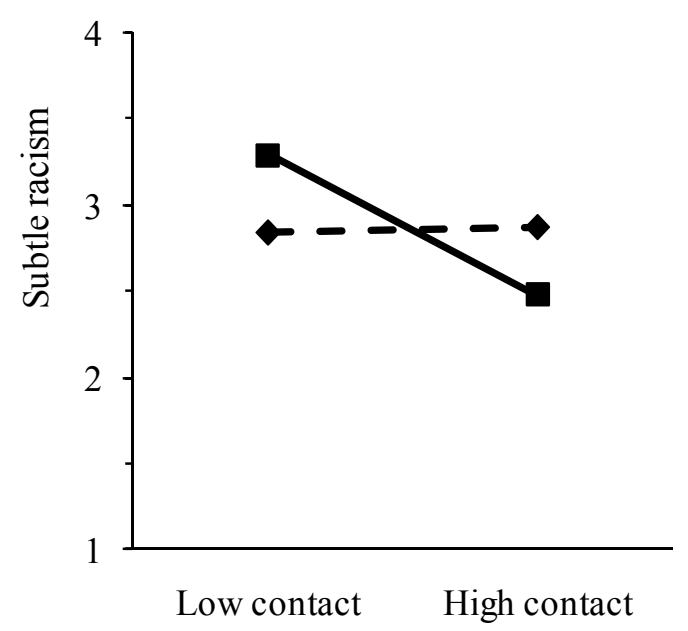

$\smile \bullet$ Low Need for Closure

$\rightarrow$ High Need for Closure 
Figure 2

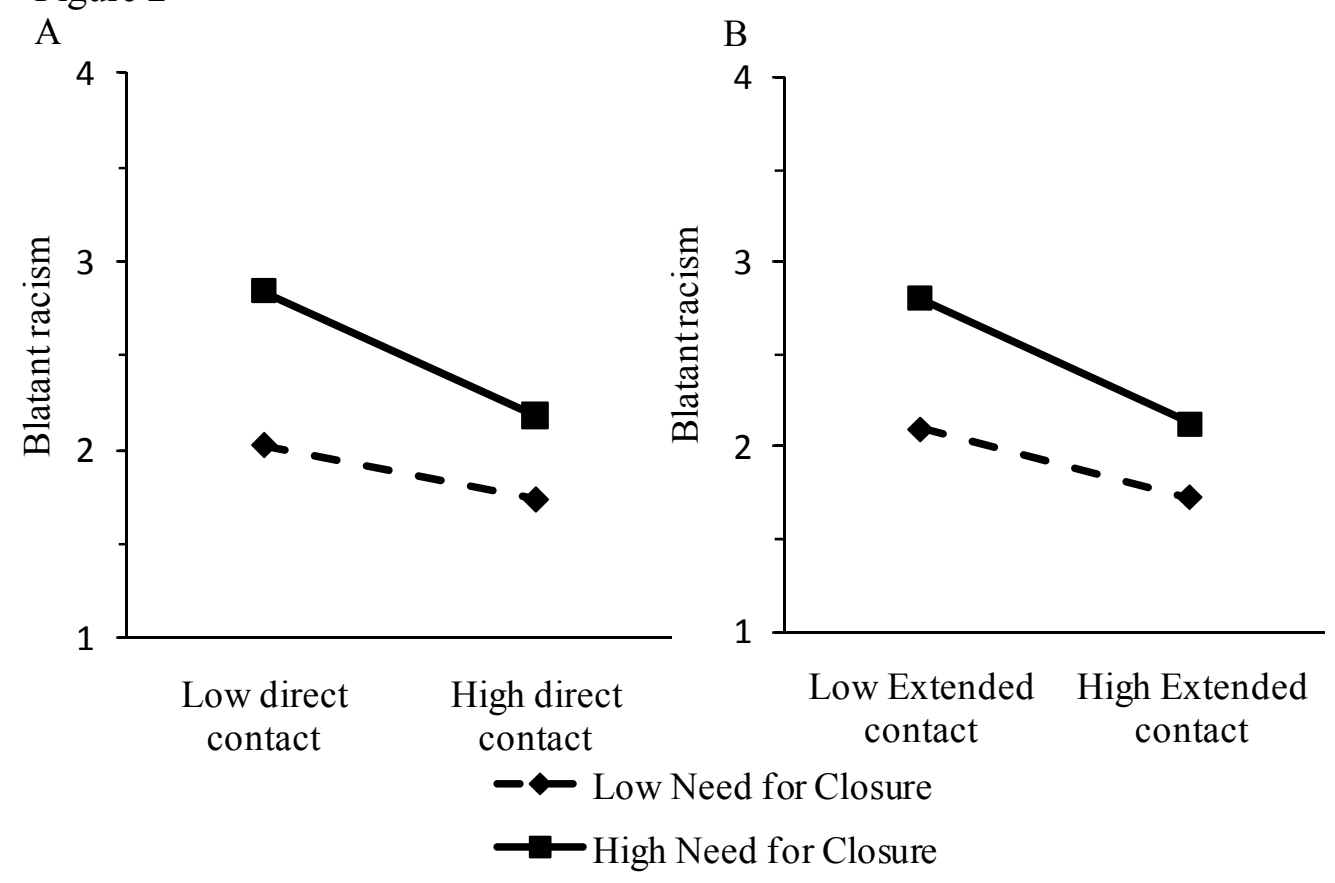


Figure 3

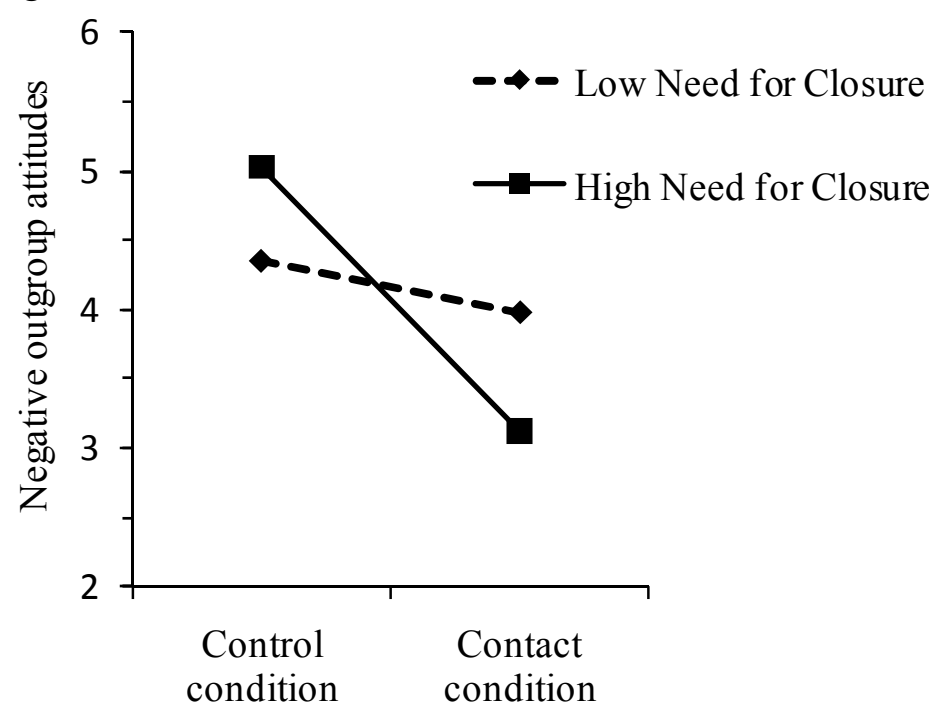


Figure 4
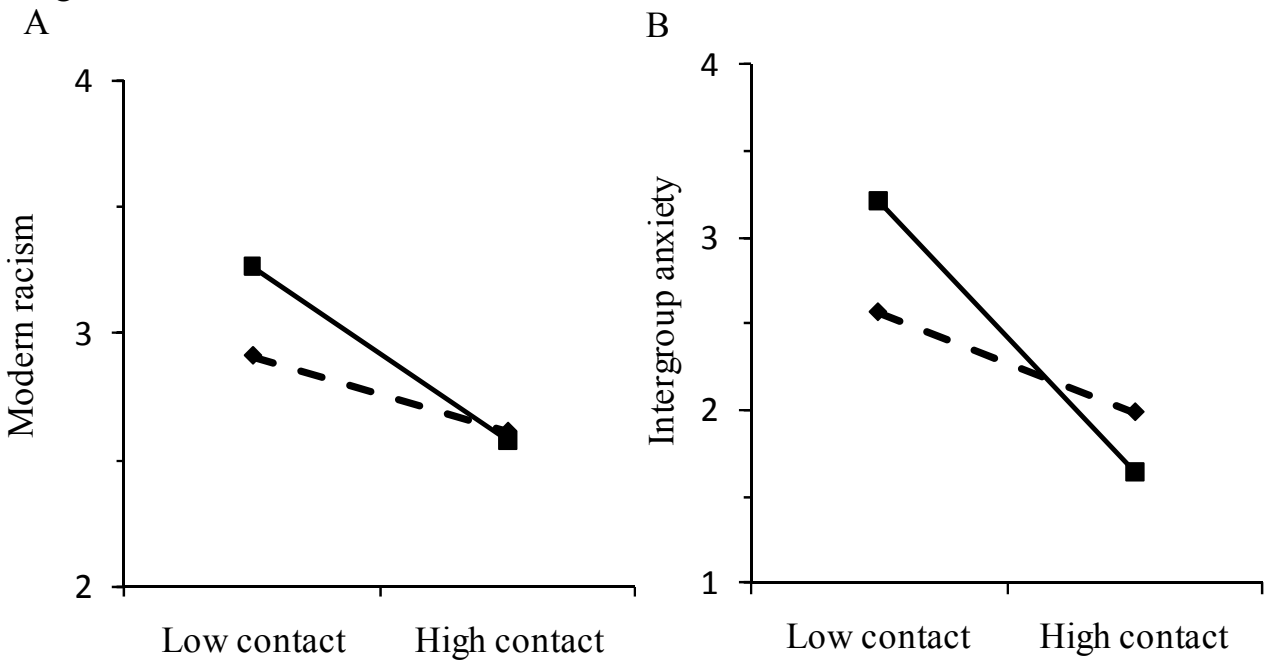

$-\infty$ Low Need for Closure

$\rightarrow$ High Need for Closure 
Figure 5
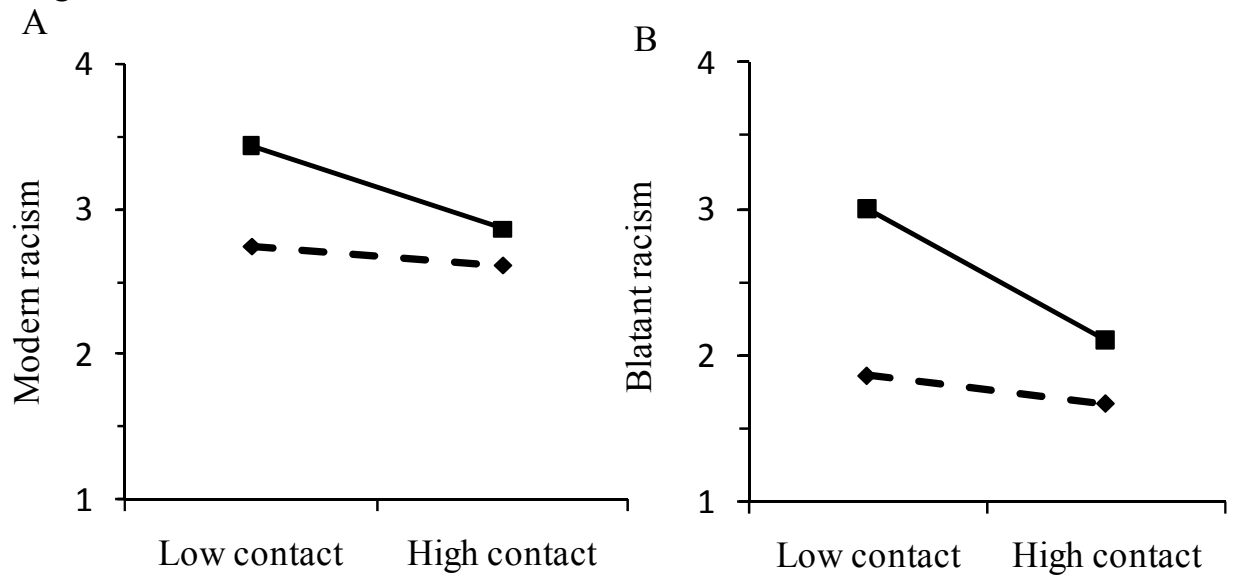

$\_$Low Need for Closure

$\longrightarrow$ High Need for Closure
